\title{
A Practical Electric Arc Furnace Model for Computer Simulation
}

\author{
Lixia Zhang1, Wei Kang1, Xiaoping Zhang2 \\ ${ }^{1}$ China University of Petroleum, Qingdao, China \\ ${ }^{2}$ University of Birmingham, Birmingham, UK \\ Email: zhanglixia@upc.edu.cn,kangwei@upc.edu.cn,X.P.Zhang@bham.ac.uk
}

How to cite this paper: Zhang, L.X., Kang, W. and Zhang, X.P. (2017) A Practical Electric Arc Furnace Model for Computer Simulation. Energy and Power Engineering, 9, 445-451.

https://doi.org/10.4236/epe.2017.94B050

Received: March 4, 2017

Accepted: March 30, 2017

Published: April 6, 2017

\begin{abstract}
A practical model of electric arc furnace can help design filters to delay the use life of power line electro-insulating material. This paper proposed a practical simulation model of electric arc furnace. The model is built based on its real output characteristic. It can out put a distort current composed up of $\mathrm{n}$ harmonics and non-integer harmonics which re-appear the arc's cutting off and short circuit phenomenon in melting stage. The current can be set to extrude unbalanced current, interrupted current and half wave imbalance current of each phase. It can also simulate the voltage distortion and flicker effect to other loads. A flicker measure plat is carried out and the model proved to be feasible and realizable. It can realize electric arc furnace output characteristic and is easier to be connected to the power system.
\end{abstract}

\section{Keywords}

Electric Arc Furnace, Electrical Appliance, Electro-Insulating Material, Insulation

\section{Introduction}

As one of the important steel smelting equipment, electric arc furnace affects the quality of steel products directly. It also influenced power line electro-insulating materials' use life in cause of the harmonics that injected to power system. Today, because of the energy shortage and lack of resources, energy-saving and reduction of consumption of electric arc furnace causes the widespread attention of public [1]. However, reactive power compensation and harmonic suppression is one of the effective measures to energy saving and emission reduction of electric arc furnace [2]. Prior to this, we should study electrical operation characteristics of AC arc furnace and apply it to the system model through the module for the whole system simulation. 
There are mainly two kinds of traditional models to simulate arc's characteristics of either resistance or emerge mechanism [3] [4]. These methods have a common shortcoming that they can't be both precise and easier to be performed. The arc furnace is harmful in power system for being a harmonic source and reactive power consumption which caused voltage stepping down. So a practical electrical should realize electric arc furnace output characteristic and easier to be connected to the power system [5]. This paper proposed a practical simulation model for computer simulation. It can simulate the electric arc furnace output characteristic both high order frequency and dispersed harmonic.

\section{Output Characteristic of Electric Arc Furnace}

Electric arc furnace smelts ores and metals through high temperature produced by electrode arc. The power is concentrated when gas discharges. The temperature of arc can be more than $4000^{\circ} \mathrm{C}$. When the arc begins, there is a time delay. As a load, its feature is of highly nonlinear. Those characteristic made current harmonics emerges. When smelting, the arc length often suddenly changes. This made bus voltage variation randomly. It will induce a dispersed harmonic frequency which scattered around a frequency band from 0.1 to $30 \mathrm{~Hz}$. The phenomenon can be aggravated for the continuous movement of the molten slag and mutual effect, which happen between arc and the arc of the Lorentz force especially when the metal in the ore is dissolved. When refined, although the arc characteristic is ideal, the length of arc still changes. The change is caused by fluctuation of melt metal's surface layer.

Because the three-phase electrode in electric arc furnace can't contact the ore in the same time, and the furnace is a nonlinear load, so long as the electric arc furnace connected to the grid, the fluctuation of voltage would influence the normal operation of other sets. It also includes many high order harmonics such as $2,3,4,5,7$ order et al. The average distortion rate is at $8 \%-20 \%$. The most can be $45 \%$. Higher order harmonics could not only influence power quality, but also initiate heat which can reduce electro-insulating material's property. To restrict the voltage distortion, appropriate method should be adopted.

Table 1 showed an actual measure value of electric arc furnace's current [6]. In it $n$ is harmonic order.

According to article [7], the arc temperature moves about at the range $\left(T_{0}-\right.$ $T_{\mathrm{i}}$ ), the trend is showed in Figure 1.

Table 1. Harmonics content in electric arc furnace's working current.

\begin{tabular}{cccccc}
\hline $\mathrm{n}$ & Content (\%) & $\mathrm{n}$ & Content (\%) & $\mathrm{n}$ & Content (\%) \\
\hline 2 & 10.45 & 6 & 2.4 & 10 & 0.62 \\
3 & 9.38 & 7 & 2.2 & 11 & 0.6 \\
4 & 4.56 & 8 & 1.0 & 12 & 0.45 \\
5 & 5.8 & 9 & 0.88 & 13 & 0.4 \\
\hline
\end{tabular}




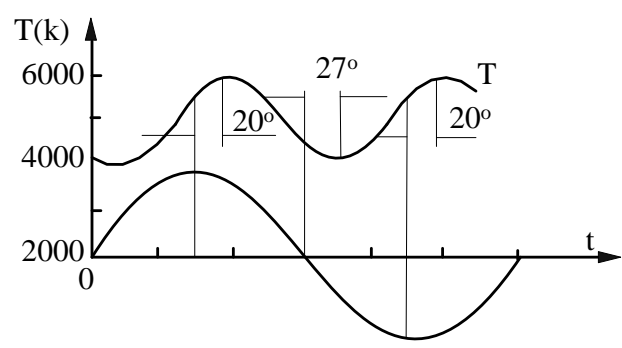

Figure 1. Relation between arc current $i$ and temperature $T$.

\section{Electric Arc Furnace Model}

\subsection{Traditional Model}

The arc temperature is expressed by

$$
T=T_{0}+\frac{T_{1}-T_{0}}{2}[1-\cos (2 \omega t+\theta+D)]
$$

where $T_{1}$ is $T_{\max }$ of arc column,

$T_{0}$ is $T$ min of arc column,

$\omega$ is angular frequency of excitation source,

$\theta$ is the angular that arc current lags behind the excitation source.

Suppose the excitation source is a sine voltage source. Its phase angular $\theta_{0}=0$. The arc resistance model $R(t)$ can be expressed as,

$$
R(t)=C L e^{\left\{T_{0} / \alpha+\left(T_{1}-T_{0}\right) / 2 \alpha[1-\cos (2 \omega t+\theta+D)]\right\}}
$$

where $A$ reflects the effect that $T_{0}$ to $R(t)$,

$B$ reflects the effect that $\Delta T$ to $R(t)$,

$C$ reflects the thermal inertia effect of arc column,

The influence of $D$ makes $R(t)$ max lags behinds somewhere after arc current $i=0$.

Traditional electric arc furnace model in power system for voltage regulation and reactive power compensation is mainly designed to reflect the high order harmonics.

\subsection{Amended Model}

This paper put forward an amended model to reflect the electrical arc furnace's dispersed harmonic. The model is based on the principle of voltage flicker. The theory that a fluctuate wave synthesized by the carrier wave and modulating wave is studied and introduced to complete the traditional model.

Because any wave can be treated as one composed by many frequency component. In order to simplify the analysis, the amended model analysis a single frequency modulating wave modulation to carrier wave.

The general expression of modulation wave is expressed as,

$$
u(t)=\left[U_{m}+m \cos \Omega t\right] \cos \omega t
$$

where $U_{\mathrm{m}}$ is the voltage amplitude of power frequency $(\mathrm{V})$ 
$\Omega$ is the angular frequency of power frequency $(\mathrm{Hz})$;

$m \cos \Omega t$ is the modulating wave voltage $(\mathrm{V})$

$\omega$ is the angular frequency of the modulating wave

The amended model is showed in Figure 2. Figure 3 compared the output current output by the traditional and the amended electric furnace model. Figure 3(a) is by the traditional model and Figure 3(c) is by the amended model $(\mathrm{m}=0.25)$. Figure $3(\mathrm{~b})$ and Figure $3(\mathrm{c})$ is the according enlarged wave of a power cycle at the time range of $0.015-0.035$. Figure 3(e) and Figure 3(f) is the according FFT analysis result.

Figure 3 showed that both models can reflect the high order frequency. The amended model has a merit to reflect dispersed harmonic. The envelop line in Figure 3(c) showed that there is a dispersed harmonic modulation to the carrier wave. It can be tested by a flicker-testing system in following simulation.

\section{Flicker Testing System}

Figure 4 showed a flicker testing system what applied to test the electrical fur-

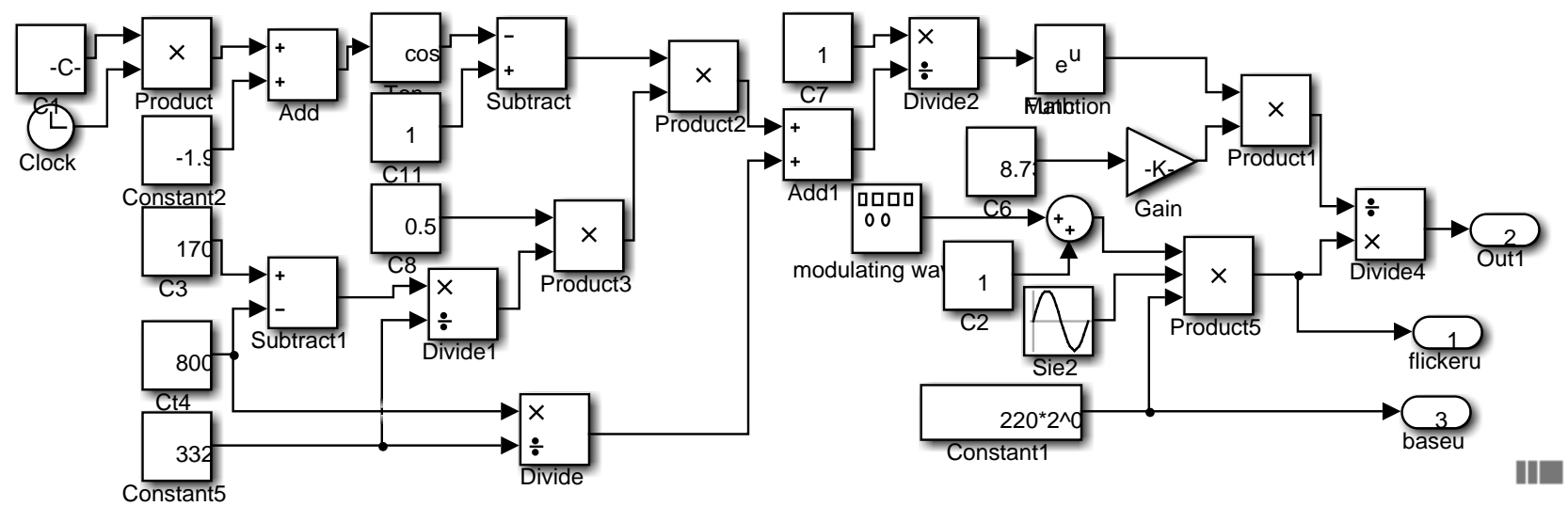

Figure 2. The amended electrical arc furnace model.
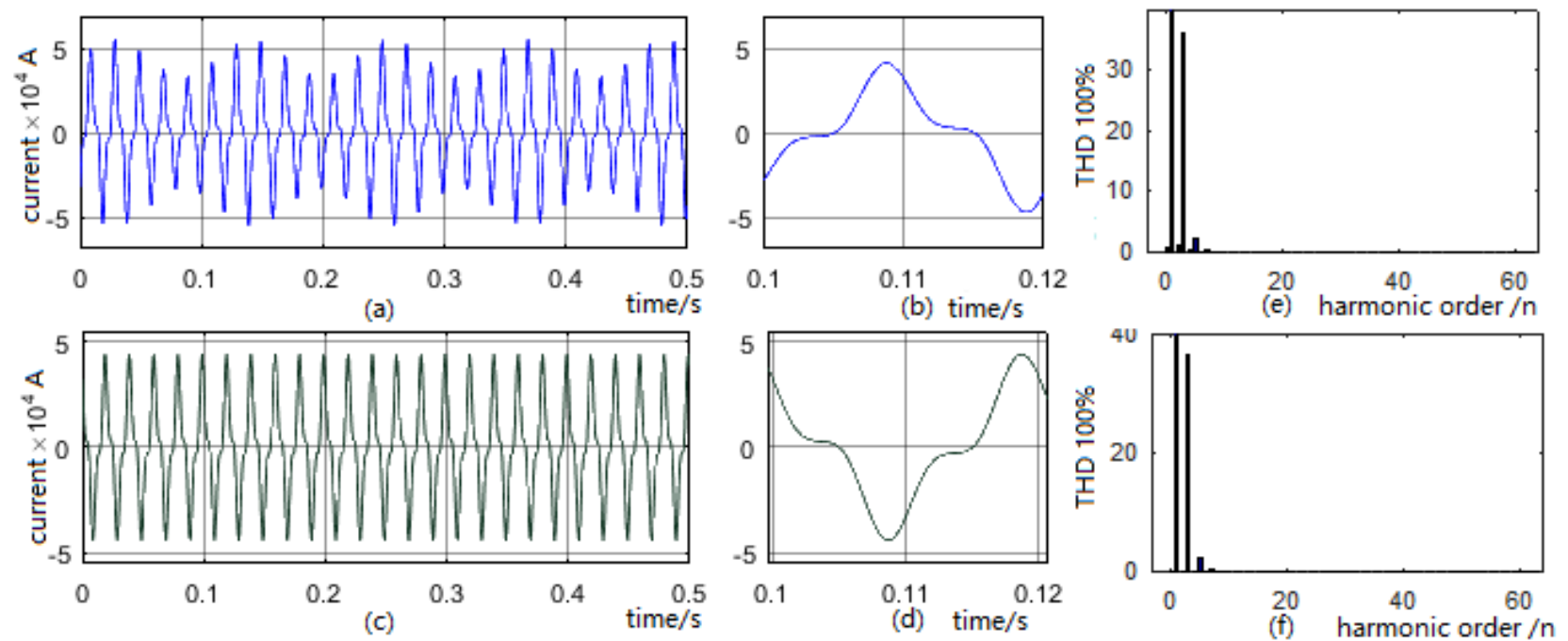

Figure 3. The output current of both models. 
nace's output current. Figure 5(a) showed the traditional model's electrical arc furnace's output current. Figure 5(b) showed the accordingly instantaneous flicker visual sensitivity (S), and Figure 5(c) the current FFT outcome. Traditional model in Figure 5 can can reflect the harmonic characteristic precisely, but can't reflect the dispersed harmonic.

Figure 5 proved that the model can simulate output characteristic of an electrical arc furnace. It can reflect disturb to grid via both high order frequency and dispersed harmonic.

Figures 6-8 showed when the modulating wave's frequency is $0.5 \mathrm{~Hz}, 5 \mathrm{~Hz}$ and $8.8 \mathrm{~Hz}$, and $\mathrm{m}=0.0025$, the different correspond instantaneous flicker visual sensitivity.

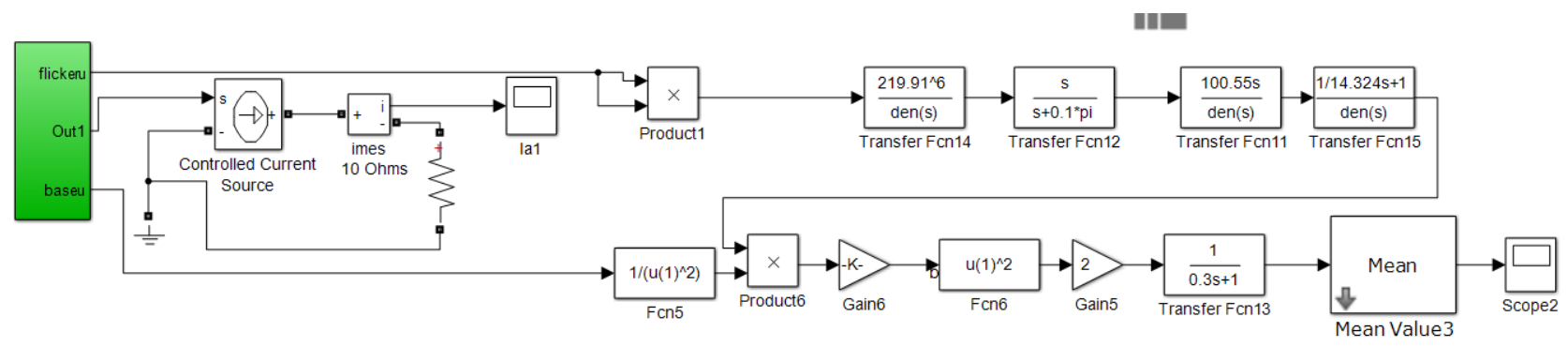

Figure 4. Flicker detecting system for the electrical arc furnace.

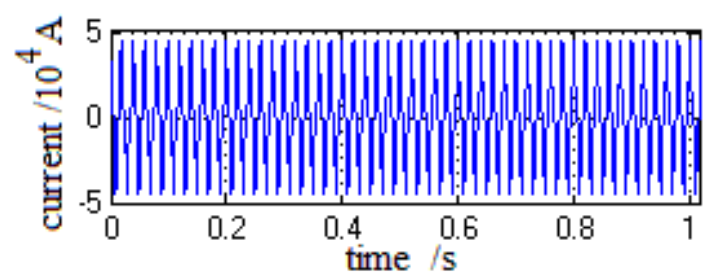

(a)

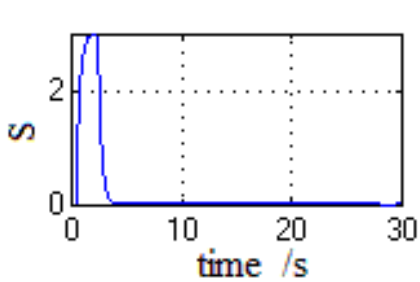

(b)

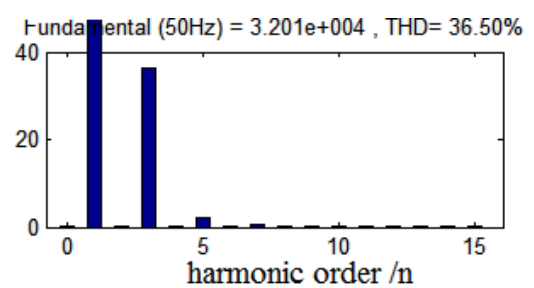

(c)

Figure 5. The output and analysis of traditional model.
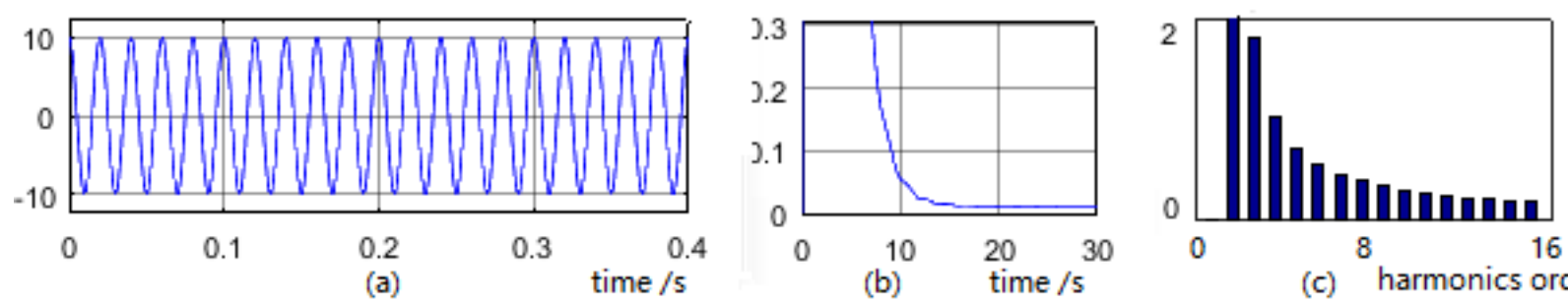

(c) harmonics order/n

Figure 6. The output and analysis result of amended model $(f=0.5 \mathrm{~Hz})$.
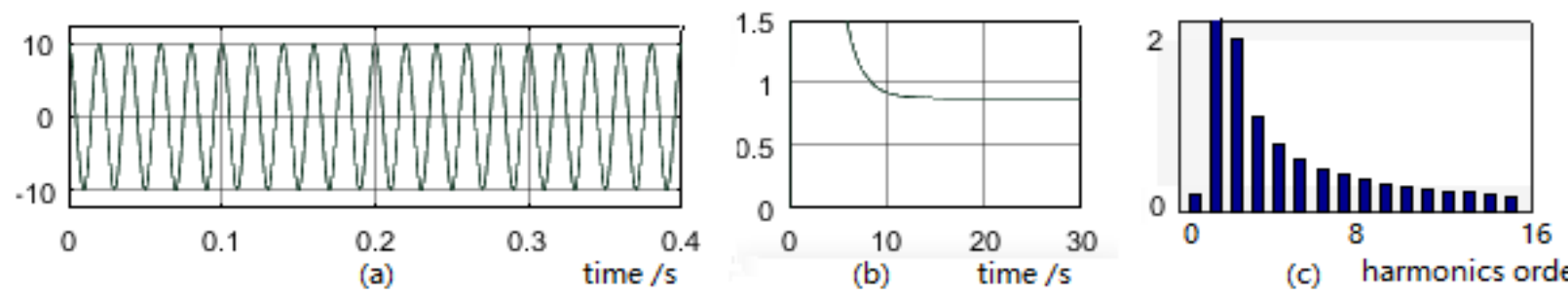

(c) harmonics order/n

Figure 7. The output and analysis result of amended model $(\mathrm{f}=5 \mathrm{~Hz})$. 

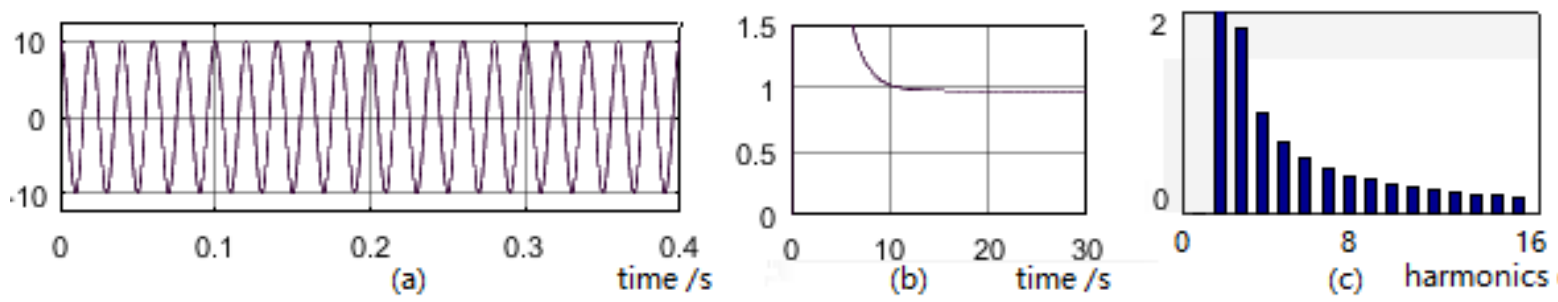

(c) harmonics order/n

Figure 8. The output and analysis result of amended model $(\mathrm{f}=10 \mathrm{~Hz})$.

Because the modulating waves in Figures 6-8 are of the same amplitude at different dispersed frequency, the electrical arc furnace output currents has a common current THD. But the instantaneous flicker visual sensitivity $S$ is not equal. The closer the modulating wave frequency to $8.8 \mathrm{~Hz}$, the larger $\mathrm{S}$ is.

\section{Summary}

This paper introduced a practical simulation model for computer simulation. It simulates the electric arc furnace output characteristic by a CCCS model. The output current has harmonic component of both high order frequencies and dispersed harmonics. The characteristic is more close to the real electric arc furnace property. A flicker testing model is established to test the instantaneous flicker visual sensitivity S. Modulating waves of different frequencies and the same amplitude is introduced to test the correctness of the model. It can help to establish a more practical model to simulate a wide output range of harmonics. It would be more help full for harmonic-preventing sets such as active power filter (APF) to test their characteristics. The power system would be more reliable and Electro-insulating material will have a longer using life. The method is proved to be reasonable and realizable to reflect the real electric arc furnace property.

\section{Acknowledgements}

Supported by National Science Foundation (51207170), the Fundamental Research Funds for the Central Universities (14CX02172A) and National Science Foundation (61271001).

\section{References}

[1] Liu, H.D., Zhang, D.H. and Tang, J.Y. (2012) Research on Direct Voltage Control of STATCOM for Mitigating Electric Arc Furnaces Flicker. Transactions of China Electrotechnical Society, 27, 41-47.

[2] Xu, S.K., Song, Q., Liu, W.H., et al. (2007) Research on the Power Quality Problems and Compensation Scheme for Electric Arc Furnace in Distribution Supply System. Proceedings of the CSEE, 27, 93-98.

[3] Mokhtari, H. and Hejri, M. (2002) A New Three Phase Time-Domain Model for Electric Arc Furnaces Using MATLAB. AsiaPacific Transmission and Distribution Conference and Exhibition, Yokahama.

[4] Kang, J., Shao, Z.G., et.al. (2010) Analysis on AC electric Arc Furnace Flicker and Its Influencing Factors. Journal of Electric Power Science and Technology, 25, 66-71. 
[5] Kang, W., Yan, X.W., et al. (2009) Research on Sampling Frequency of Flicker Measurement. Electrical Measurement \& Instrumentation, 46, 1-5.

[6] Sun, W.H., Chen, L. and Yuan, X.D. (2013) Harmonic Effect and Strategy Analysis of Metallurgical Enterprises Centralized Connected to Distribution Gird. Jiangsu Electrical Engineering, 32, 46-53.

[7] Sun, W.H., Chen, L. and Yuan, X.D. (2013) Harmonic Effect and Strategy Analysis of Metallurgical Enterprise Centralized Connected to Distribution Gird. Jiangsu Electrical Engineering, 3.

Submit or recommend next manuscript to SCIRP and we will provide best service for you:

Accepting pre-submission inquiries through Email, Facebook, LinkedIn, Twitter, etc. A wide selection of journals (inclusive of 9 subjects, more than 200 journals) Providing 24-hour high-quality service User-friendly online submission system Fair and swift peer-review system Efficient typesetting and proofreading procedure Display of the result of downloads and visits, as well as the number of cited articles Maximum dissemination of your research work

Submit your manuscript at: http://papersubmission.scirp.org/ Or contact epe@scirp.org 